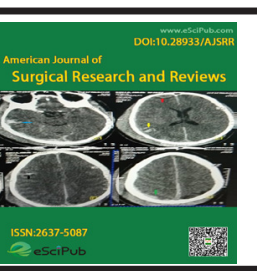

American Journal of Surgical Research and Reviews

(ISSN:2637-5087)

\title{
Modifications of Paramedian Forehead Flap
}

Faisal Ashfaq, MBBS, FCPS (Plastic Surgery), FRCS (Plast) ${ }^{1}$; Atif Rafique, MBBS, FCPS (Plastic Surgery), FEBPRAS (Plastic), MPA ${ }^{2}$; Ambreen Arshad, MBBS, MCPS, MPA ${ }^{3}$

${ }^{1}$ Locum Consultant Plastic Surgery, Bradford Teaching Hospital Trust, Bradford D96RJ; ${ }^{2}$ King Faisal Specialist Hospital and Research Centre Riyadh Saudi Arabia; ${ }^{3}$ Consultant primary health care.

\section{ABSTRACT}

Introduction Paramedian forehead flap an interpolated flap based on supratrochlear ves-sels is considered as a workhorse for nasal and periorbital reconstruction however it re-quires modification's to meet reconstruction requirement. Modifications includes islanded single stage forehead flap, expanded forehead flap, pre-fabricated with rib cartilage, folded forehead flap, split forehead flap and delayed flap, are associated with complica-tions which can be minimized using different techniques. This article's objective is to re-view indications for modification of Paramedian forehead flap, its complications and techniques of minimizing them. Methods: Twenty-three patients with facial defects reconstructed with modified Paramedi-an forehead flap were analysed by non-probability purposive sampling from September 2010 to August 2014, while traditional forehead flap reconstructions were excluded. Results: Nasal and periorbital region defects were present in twenty-one and two pa-tients respectively.13 had full thickness nasal defects, 14 had BCC while SCC in 2 pa-tients. Reconstruction was performed in multiple stages except in three patients. Expand-ed forehead flap was used in four, subcutaneously islanded pedicle forehead and flap prefabricated forehead flaps in three each, split forehead and delayed reconstruction in two patients each. No total loss of flap was observed except in one folded forehead flap where partial distal one $\mathrm{cm}$ necrosed; one patient with expanded forehead flap required revision due to flap contraction. Conclusions: Modifications of Paramedian forehead flap appear reliable, versatile and excellent tool for nasal and periorbital reconstruction. Judicious modifications of flap de-sign as per indication can give satisfactory results with minimal complications by follow-ing the techniques mentioned in literature.

Keywords: forehead flap; modifications; complications.
*Correspondence to Author:

Atif Rafique, MBBS, FCPS (Plastic Surgery), FEBPRAS (Plastic), MPA King Faisal Specialist Hospital and Research Centre Riyadh Saudi Arabia

How to cite this article:

Faisal Ashfaq, Atif Rafique, Ambreen Arshad. Modifications of Paramedian Forehead Flap. American Journal of Surgical Research and Reviews, 2021, 4:16

\section{eScîPub}

eSciPub LLC, Houston, TX USA. Website: https://escipub.com/

By using the site/services, you are agreeing to our Policies:

https://escipub.com/terms-privacypolicy-disclaimer/ 


\section{INTRODUCTION}

Paramedian forehead flap based on supra trochlear vessels has been considered as ideal workhorse for nasal or peri-orbital reconstruction because of its good colour match and texture ${ }^{1}$. Traditionally it has been used as an interpolated forehead flap performed in two stages spaced three weeks apart.

However, in various case series and reports, diverse modifications for varying reconstructive needs have been described including single stage forehead flap passing the pedicle subcutaneously ${ }^{2}$, folded forehead flap ${ }^{3}$, split forehead flap $^{4}$ to reconstruct both eyelids defect simultaneously, prefabricated with cartilage grafts ${ }^{5}$, expanded forehead flap and delayed flap ${ }^{6}$. Each of these modifications is associated with complications, which may lead to unsatisfactory outcome.

The purpose of the study was to review frequency and type of complications, methods adopted to minimize encountered complications on the basis of current literature with their outcome.

\section{METHODS}

This retrospective study, using non-probability purposive sampling technique was carried out from September 2010 to August 2014 at Jilani Hospital, Quetta, Pakistan. Patients were consented for publication and the research received approval from the Hospital Ethical committee. Case records of 45 patients who underwent reconstruction with 49 forehead flaps were analysed; Twenty-three patients with nasal and periorbital region defects reconstructed with modified Paramedian forehead flap were included in the study while patients undergone traditional forehead flap reconstructions were excluded. Patient's demographic details with aetiology of defect, type of flap used, donor site management and complications were the variables were recorded on a proforma. Outcome was measured in terms of flap survival, aesthetic result achieved and patient satisfaction score. Data was analysed by IBM SPSS 20.

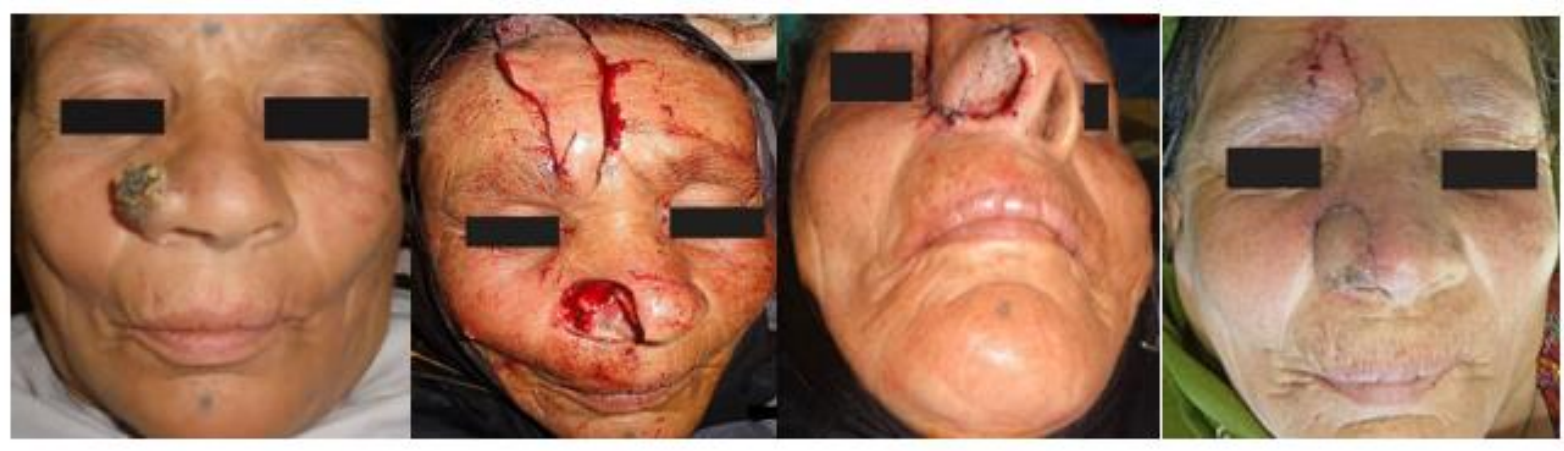

Figure $1 \mathrm{BCC}$ ala of nose involving lining (a). Defect after excision and forehead flap elevation (b). Forehead flap sutured to defect(c). Folded forehead flap after division of pedicle (d).

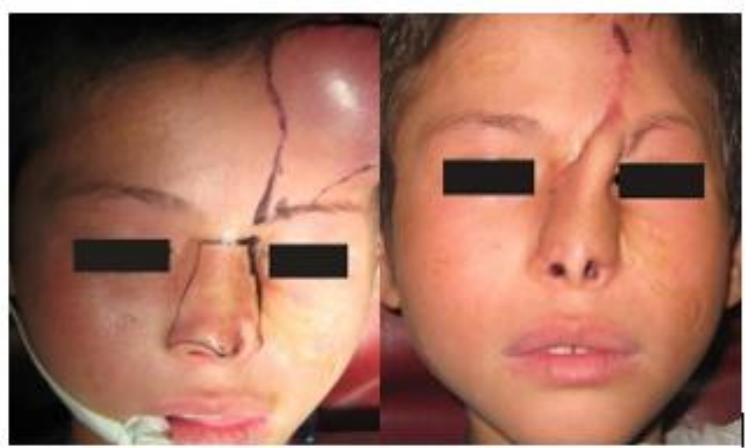

Figure 2: Post leishmaniasis scar of nose with tissue expander in forehead (a). Flap after inset and donor site closed primarily (b)

AJSRR: https://escipub.com/american-journal-of-surgical-research-and-reviews/ 
Table

\begin{tabular}{|c|c|}
\hline CLINICAL CHARACTERISTICS & $\mathbf{N}(\%)$ \\
\hline MALE & $13(56.52 \%)$ \\
\hline FEMALE & $10(43.48 \%)$ \\
\hline MEAN AGE & 50 Yrs \\
\hline \multicolumn{2}{|l|}{ DIAGNOSIS } \\
\hline BASAL CELL CARCINOMA & $14(60.86 \%)$ \\
\hline SQUAMOUS CELL CARCINOMA & $2(8.69 \%)$ \\
\hline TRAUMA \& BURNS & $3(13.04 \%)$ \\
\hline CONGENITAL & $2(8.69 \%)$ \\
\hline POST- LEISHMANIASIS & $1(4.34 \%)$ \\
\hline ADENOID CYSTIC CARCINOMA & $1(4.34 \%)$ \\
\hline \multicolumn{2}{|l|}{ PRIMARY SITE } \\
\hline NOSE & $21(91.30 \%)$ \\
\hline PERI-ORBITAL & $2(8.69 \%)$ \\
\hline \multicolumn{2}{|l|}{ SUBSITE } \\
\hline COMPOSITE & $10(43.47 \%)$ \\
\hline TOTAL NASAL & $4(17.39 \%)$ \\
\hline LATERAL HALF OF NOSE & $3(13.04 \%)$ \\
\hline ALA & $2(8.69 \%)$ \\
\hline DORSUM OF NOSE & $2(8.69 \%)$ \\
\hline MEDIAL CANTHUS & $2(8.69 \%)$ \\
\hline \multicolumn{2}{|l|}{ RECONSTRUCTION } \\
\hline $\begin{array}{l}\text { EXTENDED FOREHEAD } \\
\end{array}$ & $4(17.39 \%)$ \\
\hline $\begin{array}{l}\text { SUB-CUTANEOUS ISLAND } \\
\text { CLED FOREHEAD }\end{array}$ & $3(13.04 \%)$ \\
\hline PRE-FABRICATED FOREHEAD & $3(13.04 \%)$ \\
\hline SPLIT FOREHEAD & $2(8.69 \%)$ \\
\hline DELAYED FOREHEAD & $2(8.69 \%)$ \\
\hline $\begin{array}{l}\text { FOLDED FOREHEAD } \\
\end{array}$ & $9(39.13 \%)$ \\
\hline \multicolumn{2}{|l|}{ DONOR SITE CLOSURE } \\
\hline $\begin{array}{l}\text { PRIMARY } \\
\end{array}$ & $16(69.56 \%)$ \\
\hline SKIN GRAFTED & $6(26.08 \%)$ \\
\hline BILATERAL HATCHET & $1(4.34 \%)$ \\
\hline
\end{tabular}

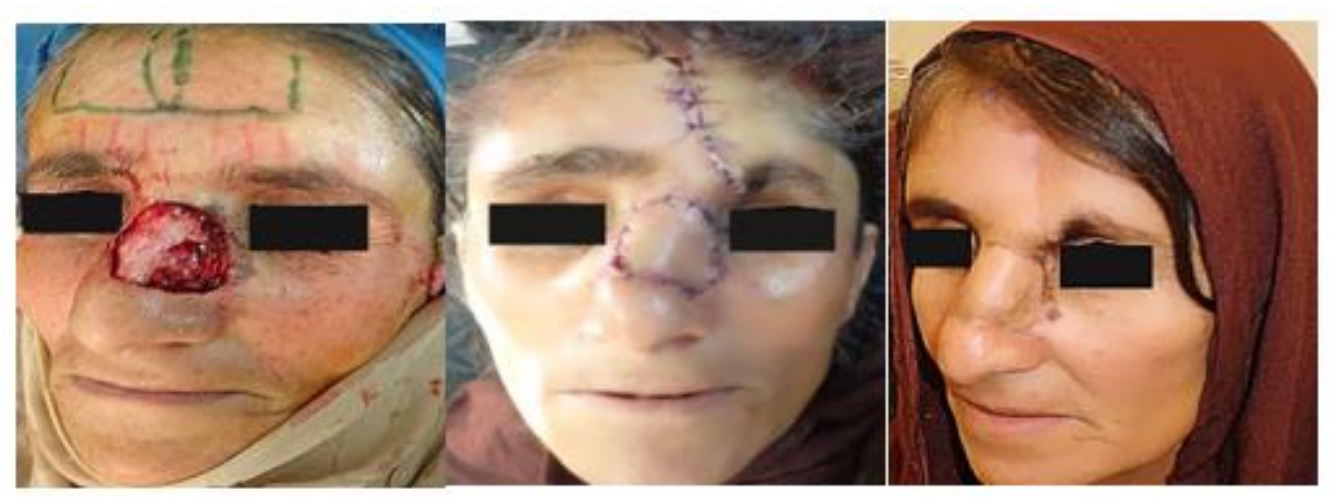

Figure 3: Nasal defect following BCC excision (a). Single stage forehead flap with inset and closure of donor site (b). Post-operative after two months (c). 


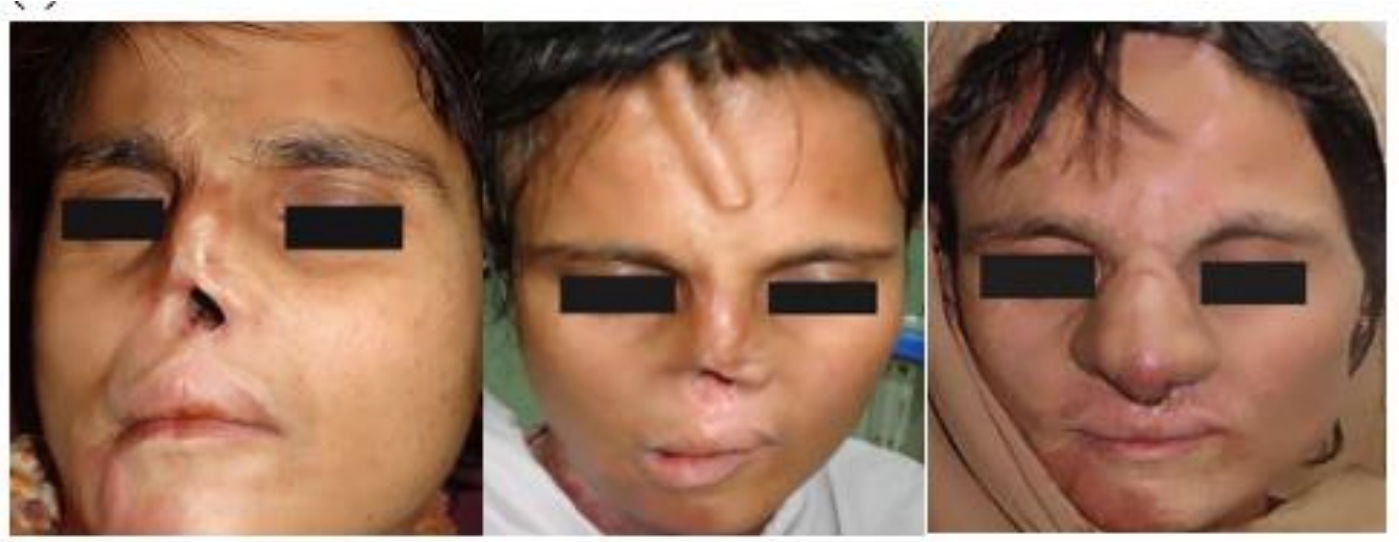

Figure 4: Post burn nasal deformity (a). Pre-fabrication of forehead flap with rib cartilage (b). Final reconstruction (c).

Figure 5: Adenoid cystic carcinoma of medial canthus and both eyelids (a). Defect after excision (b) Split forehead flap before debulking, division was performed after 3 weeks (c).

\section{RESULTS}

Modifications of forehead flap were used in 23 cases, which formed part of the study detailed in the Table. Nasal lining was reconstructed with folded forehead flap in 9 patients (figure 1). Reconstruction was performed in multiple stages except in three patients, who underwent single stage reconstruction utilizing subcutaneously islanded flap. Expanded forehead flap was used in four patients (figure 2). Subcutaneously islanded pedicled forehead flap was used in three patients (figure 3) while prefabricated forehead flaps were used in three total nasal defects (figure 4). Split forehead flaps were used in two patients for periorbital reconstruction (figure 5) and delayed forehead flap was used in two patients. Two periorbital defects following BCC excision involving both upper and lower eyelids resulted in complete medial canthus defects. Out of the nine folded forehead flaps, delayed cartilage reconstruction by conchal cartilage was performed in two patients. In two patients flaps with delayed reconstruction; one had previously undergone an oblique forehead flap for BCC reconstruction while in other case flap elevation indicated signs of poor perfusion the division of the pedicle was delayed. Donor site was closed primarily in 16 patients, skin grafted in 6 while bilateral hatchet flaps was used in one.
All patients rated their final reconstruction as satisfactory. No total loss of flap was observed however partial distal one $\mathrm{cm}$ necrosis occurred in one folded forehead flap during the second stage probably due to excessive thinning. In two patients desired alar symmetry could not be achieved with folded flap. One patient with expanded forehead flap required reconstruction redone due to flap contraction which resulted in exposure of underlying reconstructed nasal framework from rib cartilage graft and failure of the patient to report the dehiscence earlier. All patient's dorsum and lower lateral cartilage reconstruction underwent pre-fabricated rib cartilage, postoperatively flaps appeared bulky and unattractive however none of the patients returned for debulking. No complications were observed in subcutaneous islanded flaps.

\section{DISCUSSION}

Forehead flap is considered to be one of the best donor sites for nasal reconstruction because of its texture, colour match and versatility ${ }^{1}$. Paramedian forehead flap based on supratrochlear artery is the most common method of nasal reconstruction when local flaps appear inadequate. The classical procedure involves a twostage operation with division and inset the external pedicle. However varying reconstruction requirements can demand modifying traditional 
flap to obtain satisfactory outcomes but one need to be judicious while using these modifications to circumvent complications inherent with the modifications. Flap can be done single stage by subcutaneously islanding the pedicle. Forehead flap can be folded to reconstruct the inner lining. To reconstruct large areas additional tissue can be obtained by expanded the flap utilizing tissue expanders. Occasions where nasal bony and cartilaginous framework requires reconstruction, forehead flap can be pre-fabricated with a rib cartilage. When vascularity of flap appears doubtful, the procedure should be delayed by preserving the flap at the cost of an additional procedure

Forehead flap can be performed in a single stage by tunnelling the pedicle subcutaneously 2,7 . The advantages of a single stage operation is it's reduced operative cost and allowing the patient to wear eyeglasses earlier ${ }^{8}$. Its limited reduced arc of rotation restricting reconstructing of dorsal nasal defects is a disadvantage. Since the pedicle is tunnelled subcutaneously its compression results in venous congestion. The excessive bulk in glabellar region may require secondary revision ${ }^{9}$ which can be addressed by performing partial resection of procerus muscle utilizing narrow pedicle of less than $1.5 \mathrm{~cm}$ and including periosteal branch of supratrochlear artery in the flap as described in literature ${ }^{7}$, which we followed in our cases, but we found dissection tedious and time consuming.

Cases utilising a large flap where donor site cannot be closed primarily or in cancer patients defect is too large for secondary healing, skin grafting becomes necessary while tissue expanders appears as an good alternative for benign lesion defects like congenital nevus, scars or burns (Figure 2). Expanded forehead flap is a good option when forehead is tight with a short vertical height of $3-4 \mathrm{~cm}$. The major operative disadvantage we confronted was unexpected recoil after transfer leading to exposure of underlying reconstructed cartilage framework necessitating revising reconstruction which could be avoided by deflating the tissue expander for two weeks after achieving maximal expansion before transferring the flap to the defect. Another suggestion is to expand the lateral forehead by using two expanders and expanding the area prospective for flap reconstruction.

Full thickness nasal defects require reconstruction of skin, cartilage framework and inner lining which can be reconstructed with various methods like skin graft on inner surface of forehead flap and folded forehead flap. To overcome the problem of thick lining as a result of this procedure, Menick proposed a three-stage procedure $^{3}$, utilizing folded forehead flap, which we employed in nine of our patients with full thickness nasal defects (figure 1). In the second stage, incision is made along alar margin, and forehead flap is completely separated, underlying portion of flap is thinned as required which is then incorporated as a lining and conchal cartilage graft is used for lower lateral cartilage replacement. The obvious advantage of this technique is being easy, safe and doesn't require another flap ${ }^{10}$. The difficulty we encountered was a failure in achieving symmetrical nostril aperture and ala, which requires more experience.

Full thickness nasal defects after hemi and total rhinectomy poses greater challenge since they require three-dimensional reconstruction of Osseo-cartilaginous framework along with providing nasal lining. It may require multiple flaps and even microsurgical expertise, but a prefabricated Paramedian forehead flap can solely suffice to reconstruct this defect ${ }^{8,11}$. We employed this technique in three of our patients (figure4). In the first stage, rib cartilage and bone was placed between subcutaneous tissue and frontalis and costal cartilages placed laterally for lower lateral cartilage reconstruction. During second stage at three weeks, forehead flap inset into the nasal defect and inner aspect skin was grafted. Flap was debulked with fixation of bone graft to the nasal pyramid at the third stage, and pedicle was divided in fourth stage. The advantage of this technique is its simplicity, utilizing one flap and obviating need for microsurgical expertise. However, the disadvantage of this flap 
being bulky requiring revision, in our experience it's not a good reconstructive option since its aesthetic results are unpleasing and is aesthetically inferior compared to nasal prosthesis. However it still remains an alternative where lining by free flap cannot be reconstructed due to lack of resources and patient is unwilling for prosthesis.

Best technique of raising a large flap and maintaining a better blood supply is by delaying it ${ }^{6}$. In patients where pedicle is absent on preoperative evaluation, delaying of forehead flap should be considered. We employed this technique in two patients (figure 3). One patient after undergone nasal BCC defect reconstructed with oblique forehead flap developed a recurrence and post excision resulted in full thickness composite nose-cheek defect. The defect was reconstructed with cheek advancement flap and forehead flap which was elevated and delayed; full thickness skin graft was sutured to frontalis for flap lining after ten days. In the second case flap appeared dusky on elevation and since this patient previously suffered partial necrosis of forehead flap, the second flap was delayed to ensure its viability.

Forehead flap can also be split in the middle to reconstruct upper and lower eyelids. Two types of split forehead flaps have been described in the literature. In the traditional type ${ }^{12}$ forehead flap is split into frontalis muscle flap and skin flap to reconstruct nose. In the second type $\mathrm{e}^{4,13}$ distal flap is split into two parts for reconstruction of the medial canthus and upper and lower eyelids simultaneously which we incorporated in periorbital reconstruction of our patients (figure 5). This method is superior to split glabellar flap in view of wider arc of rotation and being an axial flap appears more reliable which can be split safely. Its disadvantage necessitates debulking since the forehead skin is thicker than eyelid skin. Although debulking of excising the frontalis is usually performed at first stage, forehead skin still appears bulky compared to eyelid skin, and cannot give pleasing aesthetics no matter debulking is done at its best. Nevertheless, it's still the best local option for reconstructing complex medial canthal defects involving both upper and lower eyelids.

\section{CONCLUSIONS}

Modifications of Paramedian forehead flap are reliable, versatile and excellent tool for nasal and periorbital reconstruction. Judicious modifications of flap design and elevation can give satisfactory results in indicated cases and employing modified forehead flap, following the techniques can minimize complications.

\section{Conflict of Interest: None. ACKNOWLEDGEMENTS}

To the patients and Jilani hospital where the study was carried out.

\section{REFERENCES}

1. Nasal reconstruction. Menick FJ. Plast Reconstr Surg. 2010 Apr; 125(4):138e-150e.

2. Subcutaneous forehead island flap for nasal reconstruction. Ebrahimi A, Kalantar Motamedi MH, Nejadsarvari N, Shams Koushki E. Iran Red Crescent Med J. 2012 May; 14(5):271-5.

3. A new modified method for nasal lining: the Menick technique for folded lining. Menick FJ. Plast Reconstr Surg. 2002 May; 109(6):1839-55

4. Simultaneous reconstruction of medial canthal area and both eyelids with a single transverse split forehead island flap. Onaran Z, Yazici I, Karakaya El, Cavusoglu T. J Craniofac Surg. 2011 Jan; 22(1):363-5.

5. Prefabricated scalping forehead flap with skeletal support. Fujiwara M, Suzuki A, Mizukami T, Terai T, Fukamizu H. J Craniofac Surg. 2009 Jul; 20(4):1182-5.

6. Clinical outcomes of suture delay in forehead flap. Isik D, Kiroglu F, Isik Y, Goktas U, Atik B.. J Craniofac Surg. 2012 Jan; 23(1):75-7.

7. Single-stage forehead flap in nasal reconstruction. Fudem GM, Montilla RD, Vaughn CJ. Ann Plast Surg. 2010 May; 64(5):645-8.

8. 8 Revisiting the single-stage forehead flap in nasal reconstruction. Park SS. JAMA Facial Plast Surg. 2013 Sep 1; 15(5):383-4.

9. Experiences with the forehead island flap with a subcutaneous pedicle. Converse JM, WoodSmith D. Plast Reconstr Surg 1963; 31:521-7.

10. A 10-year experience in nasal reconstruction with the three-stage forehead flap. Menick FJ. J Surg Oncol. 2006 Nov 1; 94(6):509-14. 
Faisal Ashfaq et al., AJSRR, 2021 4:16

11. Three-dimensional nasal reconstruction using a prefabricated forehead flap: case report. Alagöz MS, Işken T, Sen C, Onyedi M, Izmirli H, Yücel E. Aesthetic Plast Surg. 2008 Jan; 32(1):166-71.

12. Nasal reconstruction using a split forehead flap. $\mathrm{Li}$ QF, Xie F, Gu B, Zheng D, Lei H, Liu K, Shen G, Chang TS Plast Reconstr Surg. 2006 Dec; 118(7):1543-50.

13. Split paramedian forehead flap for medial canthal reconstruction. Arvind Krishnamurthy. Nat J Maxillofac Surg. 2012 Jul-Dec; 3(2): 241-2. 